\title{
PENGASUHAN ANAK USIA 5-6 TAHUN DI KAMPUNG TAPAK LEBARSUMATERA SELATAN 2014
}

\section{MANSYUR ROMADON PUTRA}

\author{
PAUD PPs Universitas Negeri Jakarta \\ Jl. Rawamangun Muka, JakTim.E-mail: mansyurromadonputra@ rocketmail.com
}

\begin{abstract}
This research aimed conscientious to: (1) Describe fenomena of Tapak Lebar history, (2) Describe aplyed of parenting in Tapak Lebar, (3) Discribe the reason of continues cultureparenting aplyed the regeneration to child labour, (4) Dicribe impact of aplyed parenting result for unfortunate hold out concerning social behaviour(5) Discribe motoric of child labour result for unfortunate hold out in Tapak Lebar. Subject in this research are 3 childhood age of 5-6 years. This study is qualitative research with ethnographic study of research types. Data analysis used the model Spradley. The research data obtained from observation, documentation, and intervieuw.This findings of this research indicate that (1) Tapak Lebar is fenomena of the place in there the legand have a biggest sole. (2) The applyed of parenting is hard types and continues for the regeneration, (3) The reason of parent aplyed parenting to be a hard work childhood, (4)Social behaviour of child labour be over activity.(5)The motoric of child lobour beter strong and agile.
\end{abstract}

Keywords: Parenting, Social Behaviour, Motoric.

\begin{abstract}
Abstrak :Penelitian ini bertujuan untuk mencermati budaya pengasuhan turun-temurun pada kelompok sosial yang mempekerjakan anaknya sebagai pekerja batu, adapun hal yang teramati : (1) Deskripsi fenomena keunikan riwayat kampung Tapak Lebar, (2) Deskripsi budaya pengasuhan yang diterapkan orang tua, (3) Deskripsi alasan atau penyebab pengasuhan yang membudaya secara turun-temurun, (4) Deskripsi dampak budaya pengasuhan yang berakibat pada ketahanmalangan pekerja anak terhadap perilaku sosial anak pekerja batu, (5) Deskripsi akibat ketahanmalangan anak pekerja batu terhadap keterampilan motorik. Subjek Penelitian adalah anak usia 5-6 tahun yang berjumlah 3 orang. Penelitian ini merupakan penelitian kualitatif dengan jenis penelitian etnografi. Analisis data yang digunakan yaitu model Spradley. Data penelitian ini diperoleh dari observasi, dokumentasi, dan wawancara. Hasil temuan penelitian ini menunjukkan bahwa : (1) Tapak Lebar merupakan fenomena legenda setempat yang dijadikan sebagai nama wilayah, (2) budaya yang diterapkan orang tua dengan cara mempekerjakan anak merupakan budaya turun-temurun yaitu dengan cara didikan yang keras, (3) budaya mempekerjakan anak merupakan ambisi orang tua untuk membentuk ketahanmalangan anak agar terbiasa bekerja keras sejak dini dan pemanfaatan tenaga anak sebagai penyokong perekonomian keluarga, (4) proses pengasuhan yang keras membentuk perilaku sosial yang keras bagi pekerja anak, (5) keterampilan motorik anak pekerja batu cenderung lebih terampil daripada anak-anak pada umumnya.
\end{abstract}

Kata Kunci: Pengasuhan, Perilaku sosial, Motorik

$$
\text { Indonesia merupakan negara }
$$

yang memiliki keragaman budaya dan masyarakat yang majemuk, terdiri dari berbagai suku yang 
memiliki keanekaragaman pola kehidupan yang beragam, secara geologi, Indonesia merupakan negara Persebaran penduduk pergerakannya mengikuti aliran sungai, karena air yang ada di sungai dimanfaatkan sebagai sumber kehidupan. Seiring dengan berjalannya waktu persebaran penduduk mulai berpindah kedaratan namun beberapa kelompok sosial mempertahankan hidupnya di pinggir sungai, tidak hanya memanfaatkan sungai sebagai sumber air, melainkan memanfaatkan sungai sebagai sumber mata pencaharian yaitu dengan mengumpulkan batu-batu yang ada di sungai untuk dijual kembali.

Sumatera Selatan sebagai kota wisata air memiliki banyak sungai besar, satu diantara anak sungainya adalah sungai Kelingi. Hal yang menarik adalah di pinggiran sungai Kelingi tersebut banyak terdapat batu kali yang sengaja di ambil untuk dijual, uniknya pengumpulan batu-batu kali tersebutpekerjanya didominasioleh anak-anak,. Ironisnya anak-anak tersebut sengaja dipekerjakan para orang tuanya untuk dimanfaatkan maritim, yang sebagian besar wilayahnya merupakan perairan, tenaganya untuk membantu mengumpulkan dan memecahkan batu. Pengasuhan yang diterapkan dalam keluarga membudayakan anak-anak kecil untuk dipekerjakan. Keterlibatan anak-anak tersebut secara langsung maupun tidak langsung memberikan kontribusi bagi perekonomian keluarga.

Pekerja anak sebagai kuli batu di Tapak Lebar rata-rata berada pada rentang usia dini. Anak-anak disuruh bekerja sebagai pekerja batu,kondisi yang demikian banyak dilakukan oleh keluarga yang tinggal di kampung Tapak Lebar, sehingga banyak penduduk yang memiliki anak kecil dimanfaatkan tenaganya untuk dipekerjakan menjadi kuli batu. Berdasarkan keterangan penduduk setempat bahwa pemberdayaan tenaga anak-anak dalam rentang usia dini disebabkan karena dalam masa kanak-kanak anak cenderung penurut, selepas usia dewasa biasanya anak sudah sulit untuk diatur dan disuruh bekerja. 
Kenyataan ini tidak sesuai dengan hak anak.

\section{Anak Usia Dini}

Frobel (2013:14) "anak usia dini diibaratkan seperti tunas tumbuh-tumbuhan, masih memerlukan pemeliharaan dan perhatian sepenuhnya dari si juru tanam". Dalam artian bahwa anak diusianya yang dini merupakan masa fundamental yang masih perlu diarahkan, kemudian John Locke (Suntrock, 2007:7) menyatakan bahwa anak-anak diibaratkannya seperti "papan kosong" ia menyatakan bahwa pengalaman masa kanak-kanak sangat menentukan karakteristik seseorang ketika dewasa, Menurut Mulyasa (2012:16)anak usia dini adalah inidividu yang sedang mengalami proses pertumbuhan dan perkembangan yang sangat pesat, kemajuan perkembangan dan pertumbuhan yang menakjubkan.

Dari beberapa pendapat di atas dapat disimpulkan bahwa anak usia dini adalah individu yang berada pada awal perkembangan dimana bermuaranya seluruh aspek perkembangan kognitif, fisik, dan sosial emosional yang berpengaruh terhadap perkembangannya kedepan.

\section{Perilaku Sosial Anak Umur 5-6 Tahun}

Hurlock

(1992:155156)berpendapat pada usia 5-6 merupakan usia berkelompok, anak ingin bersama teman-temannya dan akan merasakan kesepian serta tidak puas bila tidak bersama temantemannya. Menurut Mulyasa (2012;30) perilaku sosial atau non sosial yang dibina pada awal masa kanak-kanak akan sangat menentukan kepribadiannya, baik melalui pengalaman yang menyenangkan maupun tidak menyenangkan, berupa hubungan dengan anggota keluarga atau dengan orang-orang diluar keluargaa.

Bandura (Santrock, 2007:50) menyatakan bahwa "Behavior can influence person/ cognitive factors and vice versa. The person's cognitive activities can influence the environment, the environment can change the person's cognition, and so on". Hal ini menyatakan bahwa perilaku dapat mempengaruhi 
seseorang, ada korelasi antara perilaku seseorang dengan lingkungan, baik kognitif terhadap lingkungan, maupun sebaliknya hingga seterusnya.

Dari beberapa pendapat teori diatas dapat ditarik kesimpulan bahwa perilaku sosial adalah tindakan interaksi antar individu dalam mebangun hubungan yang saling berkaitan, dan perilaku sosial individu dipengaruhi oleh berbagai faktor, yang paling dominan adalah faktor lingkungan atau budaya dimana individu itu berada.

\section{Motorik Anak Usia 5-6 Tahun}

Perkembangan keterampilan motorik didasari kesiapan fisik dan kematangan motorik untuk bergerak, Mulyasa (2012:24) menyatakan "perkembangan motorik bergantung pada kematangan otot dan syaraf sehingga anak akan sulit menunjukkan suatu keterampilan tertentu ketika belum matang. Hurlock (2007:150) menyatakan perkembangan motorik berarti perkembangan pengendalian gerakan jasmaniah melalui kegiatan pusat syaraf, urat syaraf dan otot yang terkordinasi. Pengendalian tersebut berasal dari perkembangan refleksi dan kegiatan massa pada waktu lahir, sebelum perkembangan tersebut terjadi, anak tetap tidak akan berdaya.

Menurut Havigurst (David L. Gallahue dan John C. Ozmun, 2006:43) "living is learning and growing is learning", ia berpendapat bahwa pertumbuhan dan perkembangan keterampilan merupakan hasil dari kebiasaan Gallahue (2006:5) mengemukakan perkembangan motorik adalah “ continuous change in motor behavior through out the life cycle, brought about by interaction among the requirements of the movement task, the biology of the individual, and the conditions of the environment.

Dari beberapa teori di atas dapat ditarik kesimpulan bahwa keterampilan motorik adalah pengendalian gerakan jasmaniah melalui kegiatan pusat syaraf, urat syaraf, dan otot yang terkoordinasi. Terjadi seiring dengan kematangan fisik, usia 5-6 tahun motoriknya berkembang sesuai usia 


\section{Anak Yang Dipekerjakan}

Khan (2013:390) berpendapat "vehemently analyzed the determinants of child labour particularly whwere the socioeconomic variableimpacts the decicion of parentsfor the choldren time utilization" ia menyatakan bahwa faktor terkuat dari anak yang dipekerjakan adalah sosial ekonomi, dimana orangtua memberdayakan anaknya untuk keperluan pembayaran sesuatu.

Fassa

(2013:390)

mengemukakan " is of the view that child labour may have positive impacts but in some situasions it affects negatively on the health and the development of the children" ia berpendapat bahwa anak yang dipekerjakan memiliki dampak positif, tapi di beberapa situasi lebih banyak dampak negatifnya terutama kesahatan dan perkembangan anak.

$$
\text { Papalia }
$$

berpendapat mengenai pekerja anak dalam bukunya A Child World ia menyatakan "Child labor laws were designed to free children from the hard work that this boy had to perform in 1929. Long hours in fields or factories kept many children from going to school and from enjoying the kind of childhood most Americans now take for granted".

Dari beberapa definisi ahli diatas dapat ditarik kesimpulan bahwa hakikat anak yang dipekerjakan adalah individu yang berada dalam rentang usia 0-18 tahun yang didayagunakan dengan tidak wajar untuk dimanfaatkan serta diambil keuntungan baik secara perekonomian.

\section{Keluarga}

Menurut Cox dan Paley (Suntrock, 2007:158), bahwa keluarga adalah subsistem-subsistem dimana didalam subsistem itu ada komponen ayah, ibu, dan anak-anak. Hubungan subsistem tersebut dapat mempengaruhi keharmonisan dan berujung pada pengasuhan yang mengahsilkan kebahagiaan.

Santrock

$(2007: 157)$

mengemukakan setiap keluarga adalah "suatu sistem-suatu kesatuan yang dibentuk oleh bagian-bagian yang saling berhubungan dan berinteraksi. Hubungan tidak pernah hanya beralngsung satu arah". 
Hurlock

$(1992: 170)$

menyatakan hubungan keluarga

mempengaruhi penyesuaian diri secara sosial di luar rumah.Pengaruh yang mendalam dari hubungan anak dengan keluarga jelas terlihat dalam berbagai bidang kehidupan, oleh sebab itu keluarga berperan penting dalam pembentukan kepribadian.

Dari beberapa definisi diatas dapat disintesiskan bahwa keluarga adalah bagian dari kehidupan individu dimana menjadi tempat untuk memperoleh perlindungan, kasih sayang, interaksi, dan pendidikan.

\section{Pola Pengasuhan}

Santrock

(2007:11)

berpendapat bahwa pengasuhan adalah bagaimana cara menentukan sikap dalam mengatur anak.Yaitu secara permisif atau otoriter.

Elizabeth Hurlock (2007:205) mengungkapkan pola pengasuhan sebagai metode yang dipilih orang tua sebagai metode pendidikan anak.Dibagi menjadi tiga yaitu pola pengasuhan otoriter, permisif, dan demokratis. Adapun ciri dari masingmasing pola tersebut adalah Pola
Pengasuhan Otoriter,Pola Pengasuhan Demokratis, Pola pengasuhan Permisif.

Menurut Baumrind (Hurlock, 2007: 2005-2015) ada empat jenis gaya pengasuhan yaitu pengasuhan otoritarian, pengasuhan otoritatatif, pengasuhan mengabaikan, pengasuhan menuruti.

Dari beberapa definisi diatas dapat disintesiskan bahwa pola pengasuhan adalah cara yang diterapkan orang oleh tua kepada anaknya dalam proses menumbuhkembangkan anak/membesarkan anaknya, secara garis besar dibagi menjadi tiga, yaitu permisif, demokratis, dan otoriter.

Beberapa hasil penelitian yang relevan dengan penelitian ini,Masayo Uji, Ayuko Sakamoto, Keichiro Adachi, Toshinori Kitamura pada penelitiannya The Impact of Authoritative, authotarian, and permisive parenting Styles on Children's later mental Helth in Japan: Focusing on parent and child gender. Pada penelitian ini melihat efek dari gaya pola pengasuhan otoriter, otoritarian, dan permisif terhadap kesehatan mental anak, perbedaan dengan penelitian yang 
dilakukan yaitu penelitian di kampung Tapak lebar melihat pola pengasuhan, dampak pola pengasuhan terhadap perilaku sosial dan motorik anak, Tayyaba Zarif, Aiz-un-Nisa, Aijaz Ahmed, Mubashir Mirza dalam peneltiannya Understanding Reasons of Child Labour In A Developing Economy: A Qualitative Study of Karachi, Pakistan. Adapun keterkaitan dengan penelitian ini yaitu sama-sama tentang anak yang dipekerjakan .

Tujuan utama dari penelitian ini adalah untuk mencermati pola pengasuhan yang diterapkan orang tua penyebab menerapkan pengasuhan dan dampaknya terhadap perilaku sosial anak serta perkembangan motorik anak.

\section{METODOLOGI PENELITIAN}

Metode yang digunakan dalam penelitian ini adalah penelitian kualitatif dengan pendektan etnografi, yaitu memfokuskan pada budaya suatu kelompok sosial dalam hal pengasuhan dan aktivitas kesehariannya, adapun tujuan utama dari penelitian jenis kualitatif ini sendiri adalah untuk meneliti kondisi objek yang alamiah, peneliti sebagai instrumen kunci (key instrumen).

Teknik pengumpulan data dilakukan dengan berbagai cara yaitu dengan cara pengamatan langsung observasi berperan serta, wawancara mendalam, dan mengumpulkan berbagai dokumen terkait dengan pengasuhan, wawancara dilakukan dengan informan dan subjek penelitian dengan pendekatan wawancara tidak terstruktur dan pendekatan informal, analisis data bersifat induktif, dan hasil penelitian kualitatif lebih menekankan makna daripada generalisasi. Sumbersumber data dari penelitian ini antara lain: Masyarakat budaya : Tokoh Masyarakat, tokoh adat, masyarakat setempat dan budaya masyarakat kampung Tapak Lebar. Subjek penelitiannya adalah anak usia 5-6 tahun. Lokasi sosial dalam penelitian ini adalah masayrakat kampung Tapak Lebar yang terletak di kelurahan Tapak Lebar kecamatan Lubuklinggau barat II, Provinsi Sumatera Selatan.

Prosedur penelitian ini secara garis besar dilakukan melalui empat tahapan kegiatan, yaitu tahap pra- 
lapangan, pelaksanaan, analisis data, dan diakhiri dengan penulisan laporan, seperti yang diungkapkan Moleong (2010:127) bahwa penelitian kualitatif terdiri dari dari tahap pra-penelitian dan tahap pekerjaan lapangan. Pada tahap pekerjaan lapangan mengacu pada tahapan analisis data yang digunakan yaitu mengacu pada penelitian analisis etnografi.
Analisis data yang digunakan adalah analisis data model Spradley, analisis data dilakukan sejak sebelum memasuki lapangan (studi pendahuluan) ketika dilapangan dan ketika selesai dilapangan, untuk keakuratan data juga divalidasi dengan triangulasi dari berbagai sumber data, adapun tahapan yang dilakukan pada saat analisis mengacu pada model Spradley berikut (Sugiyono (2007: 254):

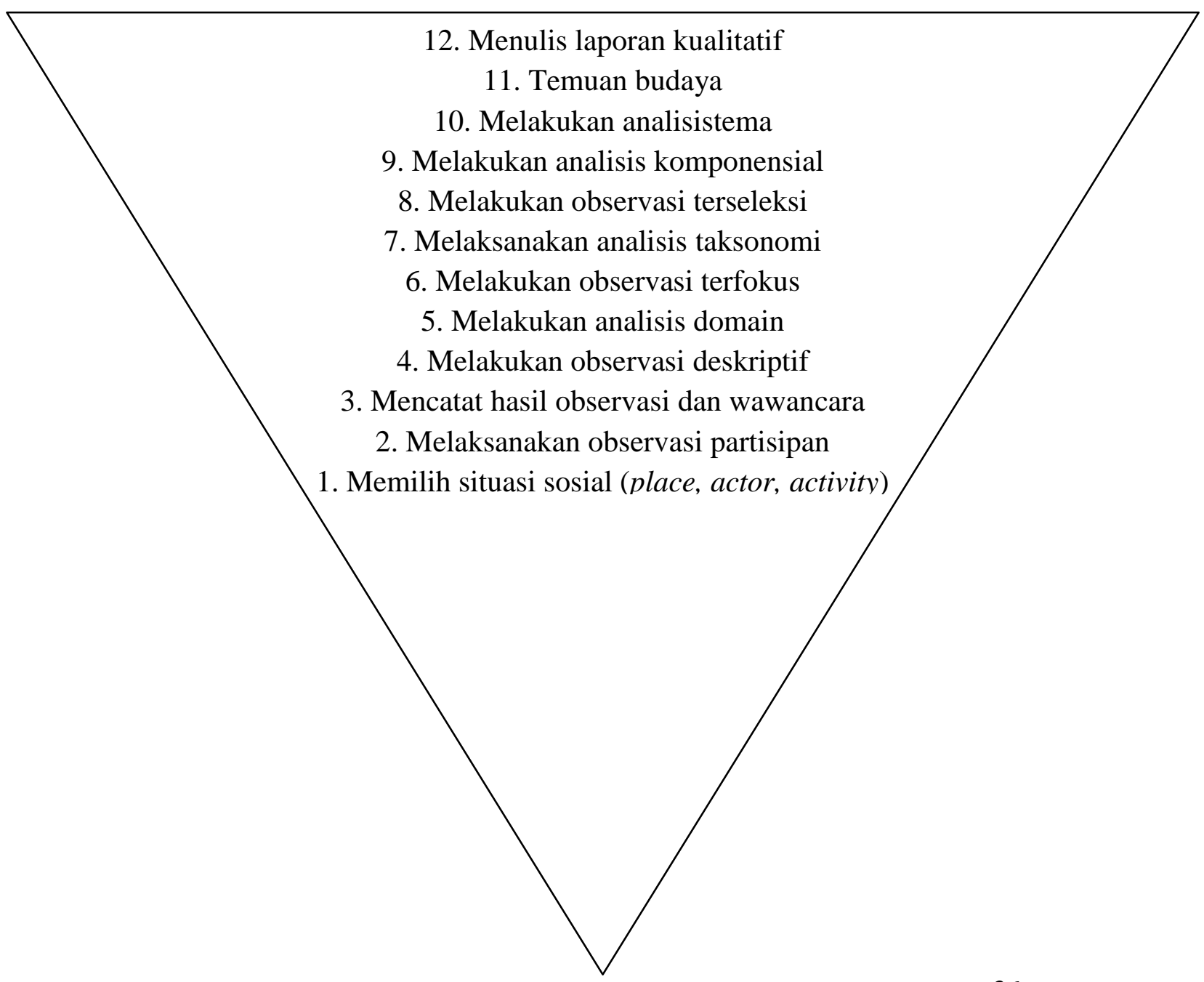


Gambar 1. Tahapan Analisis Model Spradley

\begin{abstract}
Tahapan-tahapan diatas dilakukan secara runtut dari nomor urutan pertama hingga urutan terakhir, analisis data dimulai dari domain-domain yang ditemukan dilapanagn dari berbagai sumber pengumpulan data dan dengan mengajukan pertanyaan grand tour dan mini tour, kemudian dilanjutkan dengan analisis taksonomi, berdasarkan dengan analisis taksonomi kemudian dilanjutkan dengan analisis komponensial lalu menentukan tema dan menulis hasil laporan hasil penelitian yang ditemukan.
\end{abstract}

\section{HASIL DAN PEMBAHASAN}

Dari pengamatan yang telah dilakukan maka didapat hasil dan temuan penelitian sebagai berikut.

\section{Riwayat Kampung Tapak Lebar}

Tapak Lebar merupakan nama suatu wilayah di kawasan Lubuklinggau barat II yang diambil dari nama sebutan untuk seorang pemuda yang baik hati, legendanya pemuda tersebut memiliki ukuran telapak kaki yang lebar.

Asal mula nama Tapak Lebar diambil dari legenda pemuda yang baik hati konon diceritakan memiliki telapak kaki yang berukuran lebar (diatas ukuran rata-rata), penduduk meyakini hal tersbut berupa kelebihan yang dimiliki pemuda tersebut (read: Bujang Kurap) bila dikaitkan dengan ilmu pengetahaun bahwa banyak faktor yang mengakibatkan perkembangan fisik individu, terlepas dari mitos yang dipercayai penduduk setempat, secara ilmiah bahwa lingkungan dan kebiasan juga dapat mempengaruhi perkembangan fisik terutama pada kaki yaitu tempat tumpuan organ tubuh untuk berdiri, mengingat penduduk sekitar berdomisili di wilayah sekitar sungai dengan medan yang licin, seperti yang dikemukankan oleh Hurlock (2007:8)bahwa "perkembangan dipengaruhi oleh perubahan budaya". Dalam konteks secara menyeluruh dari setiap aspek perkembangan bahwa budaya dan lingkungan ikut 
berperan dalam memberi pengaruh terhadap perkembangan dan pertumbuhan, terutama pada perkembangan motorik anak, dimana perilaku dan kegiatan yang melibatkan motorik anak secara rutin menjadi stimulasi perkembangan motorik, terasah dan terlatih.

Tapak Lebar diadopsi dari nama sebutan pemuda yang baik hati, karena riwayat kebaikannya dan diwilayah tersebut merupakan tempat peradaban si Tapak Lebar, maka kampung tersebut diberi nama Tapak Lebar oleh penduduk, dengan tujuan untuk mengenang dan menghormati si pemuda Tapak Lebar atau yang sering juga disebut dengan bujang kurap, namun bujang kurap memiliki konotasi yang kurang pantas sehingga diambillah nama Tapak Lebar sebagai nama tempat.

Pola Pengasuhan yang diterapkan oleh Orang Tua Pada Pekerja Anak Usia 5-6 Tahun di Kampung Tapak Lebar

Pengasuhan yang diterapkan orang tua terhadap anak-anak dominan otoriter dengan cara menyuruh anak bekerja keras sejak kecil tanpa pertimbangan resiko yang terjadi.

Pengasuhan yang diterapkan masyarakat kampung Tapak Lebar terhadap anak-anak berdasarkan hasil triangulasi dan refleksi peneliti dengan informan bahwa penduduk Tapak Lebar pada umumnya menerapkan pola pengasuhan dengan gaya didikan yang keras, gaya pengasuhan ini dominan mengarah pada pola pengasuhan otoriter, adapun indikasi dari pengasuhan tersebut adalah setiap orang tua ratarata memaksakan anaknya untuk bekerja keras sebagai kuli batu yang tidak sesuai dengan umurnya. Pemakasaan bekerja terhadap anak ditandai oleh 1). mewajibkan anak untuk berangkat kesungai untuk memungut dan mengumpulkan batu, 2). Mentargetkan jumlah batu yang harus terkumpul tanpa mempertimbangkan resiko yang kemungkinan terjadi, 3) menghukum anak yang tidak bekerja atau menolak suruhan orang tua, 4) membiarkan anak bekerja di sungai tanpa pengawasan keamanan, 5) membebani pekerjaan berat pada anak. 
Memaksakan kehendak terhadap anak merupakan pola pengasuhan otoriter, menurut Hurlock (2007:205)pola pengasuhan otoriter adalah cara-cara yang digunakan dalam mendidik anak dengan mengutamakan kepemimpin an yang otoriter. Orang tua memaksa untuk patuh pada nilai-nilai mereka, cenderung mengekang keinginan anak, tidak memberi kesempatan kepada anak untuk mandiri, hak anak dibatasi namun di tuntut tanggung jawab seperti orang dewasa.

Sebagai bentuk keotoriteran nya adalah mempekerja kan anak dibawah umur, dijadikan tenaga pekerja sebagai buruh batu, anakanak menjadi korban pemaksaan kehendak dari orang tua. Selain memaksakan kehendak, bila anak tidak menuruti maka orang tua berlaku kasar terhadap anak. Dengan demikian anak melakukan pekerjaan sebagai tenaga buruh batu atas dasar paksaan dari orang tuanya.

Penyebab atau Alasan Penerapan Pola Asuh Yang Digunakan Orang Tua Pada Pekerja Anak Usia 5-6 tahun di Kampung Tapak Lebar
Penerapan pola pengasuhan dengan memaksakan anak bekerja dengan alasan untuk menumbuh kembangkan kemampuan anak agar terbiasa bekerja keras sejak kecil dan faktor perekonomian.

Adapun hal yang melatarbelakangi anak-anak yang dipekerjakan di Kampung Tapak Lebar selain faktor pembiasaan bekerja keras sejak dini agar anak menjadi tangguh yaitu perekonomian keluarga, dengan anak bekerja dapat membantu penghasilan keuangan keluarga, anak usia dini di kampung Tapak Lebar bekerja turut serta dalam menyokong perekonomian keluarga seperti pendapat yang dikemukakan oleh Khan (2013:390) yaitu "vehemently analyzed the determinants of child labour particularly whwere the socioeconomic variableimpacts the decicion of parentsfor the children time utilization" ia menyatakan bahwa faktor terkuat dari anak yang dipekerjakan adalah sosial ekonomi, dimana orangtua memberdayakan anaknya untuk keperluan pembayaran sesuatu. 
Agar anak-anak mau bekerja orang tua menerapkan pola didikan yang keras, karena dengan bersifat keras anak baru menuruti perintah dari orang tuanya. Hal yang demikian;ah yang menjadi penyebab para orang tua menerapkan pola pengasuhan dengan gaya didikan yang keras terhadap anak-anaknya.

Dengan anak bekerja sejak kecil merupakan cara dalam persepsi orang tua untuk membiasakan anaknya bekerja keras sejak kecil, selain itu anak-anak bekerja juga membantu penghasilan keuangan keluarga.

\section{Dampak Pola Pengasuhan yang} Diterapkan Terhadap Perilaku Sosial Pekerja Anak Usia 5-6 Tahun di Kampung Tapak Lebar

Pola pengasuhan yang diterapkan berdampak terhadap perkembangan perilaku sosial anak yaitu cenderung berperilaku keras dan sangat aktif.

Perilaku yang terbentuk pada anak usia dini di kampung Tapak Lebar selain di pengaruhi lingkungan tempat domisili atau budaya setempat yang mayoritas penduduknya tidak mengenyam pendidikan sejalan dengan teori yang dikemukakan oleh Bandura (Suntrock, 2007:50) bahwa "Behavior can influence person/ cognitive factors and vice versa. The person's cognitive activities can influence the environment, the environment can change the person's cognition, and so on".Hal ini menyatakan bahwa perilaku dapat mempengaruhi seseorang, ada korelasi antara perilaku seseorang dengan lingkungan, baik kognitif terhadap lingkungan, maupun sebaliknya hingga seterusnya.

Pola pengasuhan yang keras melahirkan perilaku yang keras pula, seperti temuan lapangan penelitian di lapangan dalam berinteraksi kehidupan sosial anak kampung Tapak Lebar berperilaku anarkis dan nilai-nilai etika sangat rendah. Hal ini sejalan dengan teori yang dikemukana oleh Jhon Locke (Suntrock, 2007:7)ia menyatakan bahwa pengalaman masa kanakkanak sangat menentukan karakteristik seseorang ketika dewasa.Apabila pengalaman masa kecil anak sering mendapat 
perlakuan yang keras maka tidak menutup kemungkinan pola perilaku sosial anak juga keras.

Pola pengasuhan dengan gaya didikan yang keras dalam keluarga berakibat pada perilaku anak yang arogan, hal ini sejalan dengan pendapat Mulyasa (2012:30) yaitu Perilaku sosial atau non sosial yang dibina pada awal masa kanak-kanak akan sangat menentukan kepribadiannya, baik melalui pengalaman yang menyenangkan maupun tidak menyenangkan , berupa hubungan dengan anggota keluarga dan orang-orang diluar keluarga.

Perilaku yang terbentuk pada anak usia dini di kampung Tapak Lebar selain di pengaruhi lingkungan tempat domisili yaitu kawasan tempat terasingkan dari peradaban modern juga dipengaruhi oleh pola pengasuhan, pola asuh yang keras melahirkan perilaku yang keras pula, seperti temuan lapangan penelitian di lapangan dalam berinteraksi kehidupan sosial anak kampung Tapak Lebar berperilaku anarkis dan nilai-nilai etika sangat rendah.
Keterampilan Motorik Pekerja Anak Usia 5-6 Tahun di kampung Tapak Lebar

Perkembangan motorik anak usia 5-6 tahun pekerja batu lebih pesat diatas rata-rata daripada anak pada umumnya.

Pekerjaan sebagai kuli batu yang aktivitasnya di sungai diperlukan ketangkasan motorik yang baik, berdampak pada pertumbuhan dan perkembangan fisik. Rutinitas anak untuk mengambil batu dari sungai yaitu melalui bebatuan terjal dan napal yang licin mengakibatkan perkembangan fisik mereka lebih melesat dan lebih terampil dibandingkan anak lain yang seusianya pada umumnya.

Ketermpilan motorik anak pekerja batu di kampung Tapak Lebar memiliki motorik yang terampil, kebiasaan bekerja di medan yang licin dan membutuhkan tenaga berdampak pada kematangan motorik dengan baik, yaitu berupa keseimbangan tubuh dan tenaga yang gesit dan cekatan serta terampil dalam beraktivitas yang melibatkan motorik, baik motorik halus maupun 
Secara fisik perkembangan motoriknya lebih pesat daripada anak-anak pada umumnya, hal ini akibat dari stimulus yang biasa dilakukan anak, seperti yang diuangkapkan Piaget(David L. Gallahue dan John C.Ozmun, 2006: 39) anak pada rantang usia 5-6 tahun masuk pada periode pra-operasional konkret (usia 2-7 tahun), dimana anak hanya sebatas simbol "symbolic thinking" belum memasuki periode operasional konkrit yang aktivitas anak sudah mulai tertuju pada objek atau benda-benda yang nyata tanpa berimaginasi

Sejalan dengan hal tersebut diatas Gallahue (2006:5) mengemukakan perkembangan motorik adalah " continuous change in motor behavior through out the life cycle, brought about by interaction among the requirements of the movement task, the biology of the individual, and the conditions of the environment. Yaitu kelanjutan perubahan didalam perilaku motorik dalam sirkulasi hidup dari interaksi antara kebutuhan dari tubuh dan kondisi lingkungan seseorang.
Selain hal tersebut Gallahue (2006:6) juga mengatakan bahwa "motor develovmentalists recognize that the specific physical and mechanical demands of a movement task transact with the individual (biological factors) and the environment (exsperience and learning factors)". Pada intinya perkembangan motorik individu dipengaruhi oleh dua faktor, faktor biologi dan faktor pengalaman dan pembelajaran individu.

Menurut Havigurst (David L. Gallahue dan John C. Ozmun, 2006:43) "living is learning and growing is learning", ia berpendapat bahwa pertumbuhan dan perkembangan keterampilan merupakan hasil dari kebiasaan

Dari beberapa temuan diatas dapat ditarik kesimpulan bahwa pengasuhan yang diterapkan oleh orang tua terhadap anak adalah pengasuhan otoriter, dengan alasan karena orang tuamemaksakan kehendaknya agar anak terbiasa bekerja keras sejak kecil dan mendukung pemasukan keuangan keluarga, dampak yang terjadi dari perlakuan pengasuhan yang keras 
lahirlah perilaku yang arogan dan anarkis pada anak-anak, keterampilan motorik berkembang seiring dengan pola pembiasaan atau stimulasi yang biasa dilakukan sehingga mengakibatkan perkembangan motorik lebih terampil daripada anak-anak pada umumnya.

\section{SIMPULAN}

Berdasarkan hasil pembahasan yang telah dilakukan maka kesimpulan dari penelitian ini adalah Tapak Lebar merupakan nama yang diamibil dari legenda setempat. Pengasuhan yang diterapkan orang tua terhadap anak-anak berdampak pada ketahanmalangan anak dipekerjakan, dengan cara menyuruh anak bekerja keras sejak kecil tanpa suatu pertimbangan.Pola pengasuhan yang diterapkan berdampak terhadap perkembangan perilaku sosial anak yaitu cenderung anarkis. Perkembangan motorik anak usia 5-6 tahun pekerja batu lebih pesat diatas rata-rata daripada anak pada umumnya.

\section{SARAN}

Dari temuan dan informasi hasil penelitian, maka peneliti mengajukan beberapa rekomendasi sebagai berikut :

\section{Bagi Orang Tua}

Membiasakan pengasuhan dengan cara yang tidak arogan dengan tetap mempertahankan tujuan pembiasaan bekerja keras sejak dini dengan pertimbangan tertentu yaitu dengan cara menyesuaikan dengan umur, kemampuan, dan perkembangan anak serta menanamkan sifat membantu sesama.

\section{Bagi Penentu Kebijakan}

Memperhatikan anak usia dini yang dipekerjakan dan ikut membantu pengarahan batas-batas usia anak mampu untuk bekerja

\section{DAFTAR PUSTAKA}

Asian Journal Of Science \& Humanities

Undrestanding Reasons of Child Labour In a Developing Economy: A Qulitative Study Of Karachi Pakistan, Vol. 2 (2), Oyama 2013

Gallahue David L dan John C. Ozmun, Understanding 
Motor Development Infants, Children, Adolescents, Adults Singapore: McGraw-Hill, 2006.

Direktorat Pembinaan PAUD Kerangka Besar

Pembangunan PAUD

Indonesia Periode 20112025. Jakarta: 2013.

Hildayani, Rini et. al., Psikologi perkembangan anak.

Tanggerang: Universitas

Terbuka Kementerian Pendidikan dan Kebudayaan, 2014.

Hurlock, Elizabeth B. Perkembangan Anak Jilid 1 Alih Bahasa Meitasari Tjandrasa. Jakarta : Erlangga, 2007.

, Elizabeth, Perkembangan Anak. Jakarta: Erlangga, 1996.

, Elizabeth. Psikologi Perkembangan Suatu Pendekatan Sepanjang RentangKehidupan terjemahan Istiwidayanti dan Soedjarwo Jakarta: Erlangga, 1992

Moleong, Lexy J. Metode Penelitian Kualitatif. Cet XXIX; Bandung: PT. Remaja Rosdakarya, 2011.

Morrison, George S, (Alih bahasa suci Romadhona), Dasardasar Pendidikan Anak Usia Dini, Edisi ke Lima .Jakarta:Indeks, 2012.

Mulyasa,Manajemen PAUD, Bandung: PT. Remaja Rosdakarya, 2012.

Papalia, Diane E. dan Sally Wendkos Olds, A Child's World Infancy Through Adolescence .United States of America: McGRAW-HILL, 1990.
Santrock, John W. Children ninth Edition. America : Mc Graw Hill, 2007.

, John W. perkembangan anak Jilid 1 Alih bahasa Mila Rachmawati dan Anna Kuswanti. Jakarta : Erlangga, 2007.

, John W. Perkembangan Anak Jilid 2 Terjemahan Mila Rachmawati dan Anna Kuswanti .Jakarta: Erlangga, 2007.

Sugiyono, Penelitian Kuantitatif, kualitatif dan $R \& D$. Bandung: Alfabeta, 2007. 